\title{
O HOMEM É FORMADOR DE MUNDO: MUNDO COMO CONCEITO METAFÍSICO SEGUNDO MARTIN HEIDEGGER
}

\author{
Man is the World's Maker: World as a Metaphysical Conceptaccording to Martin Heidegger
}

\author{
Susiane Kreibich *
}

\begin{abstract}
Resumo: O nosso artigo tem como objetivo apresentar a formulação do conceito de mundo no âmbito da obra Os conceitos fundamentais da metafísica: mundo, finitude e solidão, de Martin Heidegger. A partir da pergunta "o que é mundo?", Heidegger formula o conceito de mundo por consideração comparativa entre as teses "a pedra é sem-mundo", "o animal é pobre de mundo" e "o homem é formador de mundo". A tese "a pedra é sem-mundo" discute acerca dos entes materiais, os quais possuem tal constituição que a sua essência é a ausência de acesso ao ente. Já a tese "o animal é pobre de mundo" analisa o modo de ser do animal, cujo acesso ao ente se dá de maneira diversa e com limites estreitos. Por fim, a tese "o homem é formador de mundo" apresenta a caracterização da essência de mundo, sendo este a abertura do ente enquanto tal na totalidade.
\end{abstract}

Palavras-chave: Mundo, Metafísica, Ser-nomundo, Martin Heidegger.

\begin{abstract}
This paper aims to present the formulation of the concept of the world within the framework of The fundamental concepts of metaphysics: world, finitude and solitude, by Martin Heidegger. From the question "what is the world?", Heidegger conceives the world concept for comparing amongst these thesis "the stone is without world", "the animal is poor of world" and "the man is the world's maker". The thesis "the stone is without world" discusses about the material beings, which have such a constitution that their essence is the lack of access to the being. On the other hand, the thesis "the animal is poor of world" examines the animal, whose access to being occurs differently and with narrow limits. Finally, the thesis "man is the world's maker" presents the characterization of the essence of the world, being this the opening of the being as such in the wholeness.
\end{abstract}

Keywords: World, Metaphysics, Being-in-theworld, Martin Heidegger.

* Mestranda em Filosofia na Universidade Federal da Fronteira Sul (UFFS). E-mail: susikreibich@gmail.com. Telefone (54) 98127-2236.

\begin{tabular}{|c|c|l|l|l|l|}
\hline intuitio & $\begin{array}{c}\text { ISSN } \\
1983-4012\end{array}$ & Porto Alegre & Vol.10 $-\mathrm{N}^{\mathrm{o} .1}$ & $\begin{array}{l}\text { Julho } \\
2017\end{array}$ & p. 94-106 \\
\hline
\end{tabular}


Susiane Kreibich

O Homem é Formador de Mundo: Mundo Como Conceito Metafísico Segundo Martin Heidegger

\section{INTRODUÇÃ̃o}

O pensamento de Martin Heidegger é marcado pela originalidade com a qual os conceitos filosóficos são tratados. Dentre eles, o conceito de mundo é colocado em destaque. A fenomenologia heideggeriana é uma "fenomenologia da cotidianidade", a qual busca interpretar a vida fática na qual os fenômenos são manifestos. Vida fática quer dizer ser em um mundo, e sob esse aspecto, o conceito de mundo torna-se um dos conceitos fundamentais para o pensamento de Heidegger.

No paradigma heideggeriano há um ente existente concretamente que é possibilidade. A partir dessa possibilidade que esse ente mesmo é, estrutura-se a condição de possibilidade de se pensar a realidade e a questão da verdade. Heidegger formula o conceito de ser-no-mundo, e por intermédio da compreensão do modo de ser do ser-no-mundo, o conceito de mundo pretende descrever a condição de possibilidade da realidade e do ente existente concretamente. O conceito de ser-no-mundo se coloca na tentativa de encontrar uma condição de possibilidade tanto para o discurso sobre a razão, quanto para o discurso sobre a realidade.

Isto posto, o nosso artigo tem como objetivo tratar, brevemente, do conceito de mundo apresentado por Martin Heidegger na obra Os conceitos fundamentais da metafísica: mundo, finitude, solidão. ${ }^{l}$ Busca-se, com isto, compreender como o filósofo elabora o conceito de mundo por meio das três teses apresentadas, a saber: 1. "a pedra (o material) é sem-mundo"; 2. "o animal é pobre de mundo"; e 3. "o homem é formador de mundo. Para fins metodológicos, o trabalho se divide em dois momentos: 1. Contextualização do paradigma heideggeriano; e 2 . A formulação do conceito de mundo.

\section{CONTEXTUALIZAÇÃO DO PARADIGMA HEIDEGGERIANO}

O conceito de mundo (Welt) é um dos conceitos fundamentais na filosofia heideggeriana. Com ele, Heidegger busca superar a questão do esquema sujeito-objeto. ${ }^{2}$ No paradigma heideggeriano, mundo

\footnotetext{
${ }^{1} \mathrm{O}$ nosso artigo busca investigar o conceito de mundo na obra Os conceitos fundamentais da metafísica: Mundo, finitude, solidão. Porém, cabe ressaltar que Martin Heidegger também trata o conceito de mundo nas obras Ser e Tempo e Sobre a essência do fundamento. Cf. STEIN, E. Mundo vivido: das vicissitudes e dos usos de um conceito da fenomenologia. Porto Alegre: Edipucrs, 2004, p. 141: "Na sua investigação do conceito de "mundo", Heidegger explora três caminhos: 1) a análise ontológica-compreensivo-estrutural (In Ser e Tempo); 2) a análise da gênese histórico filosófica (In Sobre a essência do fundamento); 3) a análise comparativo-diferencial: mundo da pedra, mundo do animal e mundo do homem; homem: sem mundo, pobre de mundo e formador de mundo (In Conceitos fundamentais da metafísica: Mundo, finitude e solidão)." Uma vez que a nossa pesquisa se encontra em andamento, neste artigo temos como objetivo nos ater à investigação da análise comparativo-diferencial do conceito de mundo.

${ }^{2} \mathrm{O}$ esquema sujeito-objeto foi configurado ao longo da tradição filosófica e não cabe em uma investigação fenomenológica. Não há, no paradigma heideggeriano, um sujeito que se volta ao objeto ou um objeto que dependa do sujeito para ser conhecido. Cf. HEIDEGGER, M. Ontologia (Hermenêutica da facticidade). Trad. Renato
}

\begin{tabular}{|c|c|c|c|c|c|}
\hline intuitio & $\begin{array}{c}\text { ISSN } \\
1983-4012\end{array}$ & Porto Alegre & Vol.10 - No.1 & $\begin{array}{l}\text { Julho } \\
2017\end{array}$ & p. 94-106 \\
\hline
\end{tabular}


O Homem é Formador de Mundo: Mundo Como Conceito Metafísico Segundo Martin Heidegger

não é compreendido como a ideia de um mundo que a razão constrói (pura racionalidade), nem a ideia de mundo que existe como uma realidade exterior independente do sujeito. ${ }^{3}$ Este paradigma surge frente à pretensão fundamentalista de Kant e à pretensão holista de Hegel. Estas são as duas posições em torno das quais quase todos os sistemas filosóficos giram. ${ }^{4}$

De um lado, Kant produz um sistema no qual há um elemento intermediário entre o sujeito que conhece e a realidade que se quer conhecer, o qual ele denominou como fenômeno. O que é conhecido é uma síntese entre os elementos dados pela sensibilidade e os recursos do entendimento a priori, ou seja, têm-se o conhecimento do fenômeno, mas não da coisa em si. ${ }^{5}$ Com isso, Kant não fica nem numa posição empirista, nem numa posição racionalista. ${ }^{6}$ A postura kantiana é chamada de transcendental. Kant analisa as condições de possibilidade do conhecimento encontrando, pois, o seu fundamento no sujeito transcendental. ${ }^{7}$

Por outro lado, Hegel refuta as teorias do conhecimento como tentativas de fundamentação filosófica, uma vez que, segundo ele, elas permanecem aquém do movimento do espírito e da consciência. A consciência deveria produzir um movimento total sobre si mesma e se encontrar a si mesma como o

Kirchner. Petrópolis: Vozes, 2013, p. 87: "O que primeiramente deve ser evitado é o esquema: que há sujeitos e objetos, consciência e ser; que o ser é objeto do conhecimento; que o ser verdadeiro é o ser da natureza; que a consciência é o 'eu penso', portanto, egoico, a egoidade, o centro dos atos, a pessoa; que os eus (pessoas) possuem diante de si: entes, objetos, coisas da natureza, coisas de valor, bens. Enfim, que a relação entre sujeito e objeto é o que se deve determinar e que disso deve se ocupar a teoria do conhecimento."

${ }^{3}$ Cf. STEIN, E. Mundo vivido: das vicissitudes e dos usos de um conceito da fenomenologia. Porto Alegre: Edipucrs, 2004, p. 133: "Isto significa, então, que ser-no-mundo é uma espécie de expressão sintética que surgiu frente às críticas ao fundamentalismo kantiano, ao holismo hegeliano e à insuficiência das teorias da vida, das teorias psicológicas etc., que tentavam justificar a história concreta ou o caráter histórico dos sujeitos. Esse conceito de serno-mundo é um conceito que nos deu um espaço onde se coloca o conceito de um mundo vivido, que não é simplesmente um conceito de teoria do conhecimento, isto é, da justificação de proposições ou juízos para reproduzir ainda de novo a racionalidade hegeliana. Por conseguinte, é uma nova tentativa em meio à crise da razão, da verdade, do fundamento e dos conceitos metafísicos."

${ }^{4}$ Cf. STEIN, E. Mundo vivido: das vicissitudes e dos usos de um conceito da fenomenologia. Porto Alegre: Edipucrs, 2004, p. 129.

${ }^{5}$ Cf. STEIN, E. Mundo vivido: das vicissitudes e dos usos de um conceito da fenomenologia. Porto Alegre: Edipucrs, 2004, p. 127.

${ }^{6}$ Cf. STEIN, E. Mundo vivido: das vicissitudes e dos usos de um conceito da fenomenologia. Porto Alegre: Edipucrs, 2004, p. 127: "Desta maneira, Kant não fica mais nem numa afirmação simplesmente racionalista, de um sujeito que é senhor absoluto do conhecimento e da realidade, nem numa posição empirista, onde teríamos que reconhecer necessariamente a prioridade da realidade sobre os sentidos e, desta maneira, fundamentalmente o império da sensibilidade."

${ }^{7}$ Cf. STEIN, E. Uma breve introdução à filosofia. Ijuí: Ed. Unijuí, 2005, p. 152: "Kant estabelece, como fundamento de todo conhecimento válido, os juízos sintéticos a priori. Sem tais juízos, não se poderia confirmar a validez do conhecimento empírico. Este é, para Kant, o conhecimento dos fenômenos. Como isso acontece? A intuição sensível recebe, através dos sentidos, a matéria amorfa e confusa que é organizada pelas categorias a priori do entendimento. Nisso consiste propriamente a revolução copernicana de Kant: o entendimento não se conduz pelos objetos, tirando deles as formas para o conhecimento inteligível; mas os objetos são informados por formas do entendimento, existentes a priori. Somente há conhecimento objetivo quando se realiza tal processo.”

\begin{tabular}{|c|c|l|l|l|l|}
\hline intuitio & $\begin{array}{c}\text { ISSN } \\
1983-4012\end{array}$ & Porto Alegre & Vol.10 $-\mathrm{N}^{\circ} .1$ & $\begin{array}{l}\text { Julho } \\
2017\end{array}$ & p. 94-106 \\
\hline
\end{tabular}


O Homem é Formador de Mundo: Mundo Como Conceito Metafísico Segundo Martin Heidegger

fundamento absoluto. ${ }^{8}$ Para Hegel, o sistema kantiano, apesar de encontrar um fundamento, não significa a totalidade, pois há uma cisão entre o sujeito que conhece e a realidade que se pretende conhecer. ${ }^{9}$

Ambas teorias possuem suas objeções: a Hegel, com a ideia de que não é possível um sujeito absoluto, nem um sistema absoluto; e a Kant, por não ser possível afirmar uma racionalidade que é embutida num eu sensível que assegure o conhecimento humano. ${ }^{10}$ Uma vez que as teorias kantiana e hegeliana não dão conta dos processos de justificação do conhecimento humano e no processo histórico da filosofia, o que resta é uma recuperação do campo do vivido na filosofia, ou o campo histórico. ${ }^{11}$ Com isso, inicia-se uma mudança de paradigma nas teorias da consciência, substituindo-se o conceito de subjetividade, e instaurando-se o paradigma do mundo vivido, ${ }^{12}$ de ser-no-mundo e de mundo prático. ${ }^{13}$

É Husserl quem cunha o conceito de mundo vivido ou mundo da vida, relacionando-o à existência concreta, ao sujeito individual existente. A proposta husserliana busca elaborar, mediante a análise fenomenológica transcendental, ${ }^{14}$ as condições de possibilidade do sujeito vivido, através do conceito de mundo vivido reconstruído na interioridade da razão transcendental. ${ }^{15}$

${ }^{8}$ Cf. STEIN, E. Mundo vivido: das vicissitudes e dos usos de um conceito da fenomenologia. Porto Alegre: Edipucrs, 2004, p. 126.

${ }^{9}$ Cf. STEIN, E. Mundo vivido: das vicissitudes e dos usos de um conceito da fenomenologia. Porto Alegre: Edipucrs, 2004, p. 127.

${ }^{10}$ Cf. STEIN, E. Mundo vivido: das vicissitudes e dos usos de um conceito da fenomenologia. Porto Alegre: Edipucrs, 2004, p. 129.

${ }^{11}$ Cf. STEIN, E. Mundo vivido: das vicissitudes e dos usos de um conceito da fenomenologia. Porto Alegre: Edipucrs, 2004, p. 130: “[...] As filosofias da vida e a Escola Histórica nos trazem esse campo do vivido. Evidentemente, ele é o campo histórico, que não foi atingido por Kant, porque no último capítulo da Crítica da razão pura, ele a promete para o futuro ou diz que o futuro é responsável pela elaboração da história da crítica da razão pura, o que ele põe em tarefa futura. De outro lado, quando Hegel faz a história da razão, ele faz a história de uma razão absoluta."

${ }^{12}$ Quanto ao paradigma do mundo vivido, ou Mundo-da-vida (Lebenswelt), há também a clássica interpretação de Merleau-Ponty. Como o objetivo do nosso artigo é, neste primeiro momento, fazer uma breve contextualização histórica até 1940, não nos deteremos no assunto. Por ora, cabe ressaltar que a tradição ocidental entende mundo como a realidade objetiva que pode ser alcançada pela consciência graças à representação. Merleau-Ponty apresenta uma fenomenologia na qual desloca-se o conhecimento e a relação consciência-mundo para a percepção. Com isso, a experiência corporal é entendida como originária. Cf. MEARLEU PONTY, "O Filósofo e sua sombra". Os Pensadores, São Paulo: Abril Cultural, 1980, p. 247: "Meu corpo é o campo onde se localizam meus poderes perceptivos. [...] Há uma relação de meu corpo consigo mesmo que o transforma no vinculum do eu com as coisas. Quando minha mão direita toca a esquerda, sinto-a como uma 'coisa física', mas no mesmo instante, se eu quiser, um acontecimento extraordinário se produz: eis que minha mão esquerda também se põe a sentir a mão direita. Es wird Leib, es empfindet. A coisa física se anima, ou, mais exatamente, permanece como era, o acontecimento não a enriquece, e entretanto, uma potência exploradora vem pousar sobre ela ou habitá-la. Assim, porque eu me toco tocando, meu corpo reage 'uma espécie de reflexão'. Nele e por ele não há somente um relacionamento em sentido único daquele que sente com aquilo que ele sente: há uma reviravolta na relação, a mão tocada torna-se tocante, obrigando-me a dizer que o tato está espalhado pelo corpo, que o corpo é 'coisa sentiente', 'sujeito-objeto'."

${ }^{13}$ Cf. STEIN, E. Mundo vivido: das vicissitudes e dos usos de um conceito da fenomenologia. Porto Alegre: Edipucrs, 2004, p. 130.

${ }^{14}$ Cf. HUSSERL, E. A crise da humanidade européia e a filosofia. Trad. e introdução Urbano Zilles. Porto Alegre: Edipucrs, 2002, p. 39: "A fenomenologia consiste na tentativa de descrever o fundamento da filosofia na consciência na qual a reflexão emerge da vida irrefletida do começo ao fim. Podemos resumir os seguintes aspectos da fenomenologia husserliana: a) É um método derivado de uma atitude, que presume ser absolutamente sem

\begin{tabular}{|c|c|l|l|l|l|}
\hline intuitio & $\begin{array}{c}\text { ISSN } \\
1983-4012\end{array}$ & Porto Alegre & Vol.10- No.1 & $\begin{array}{l}\text { Julho } \\
2017\end{array}$ & p. 94-106 \\
\hline
\end{tabular}


O Homem é Formador de Mundo: Mundo Como Conceito Metafísico Segundo Martin Heidegger

Husserl busca estabelecer uma filosofia primeira, instaurando com isso uma ciência fundamental da subjetividade pura. Esta filosofia primeira denomina-se fenomenologia, a qual é "a ciência descritiva eidética da consciência pura transcendental ou doutrina pura descritiva das essências das estruturas imanentes da consciência". ${ }^{16} \mathrm{E}$ como uma ciência rigorosa, conduzirá às bases últimas de todas as coisas, cujo fundamento se encontra no mundo da vida.

De acordo com Husserl, as ciências europeias se encontram em crise, ${ }^{17}$ uma vez que houve o esquecimento do mundo da vida, havendo assim, uma ruptura entre o objetivismo das ciências e o subjetivismo transcendental. ${ }^{18}$ A crise será superada através da fenomenologia transcendental, ${ }^{19}$ e o seu acesso se dá a partir do mundo da vida.

pressupostos, tendo como objetivo proporcionar ao conhecimento filosófico as bases sólidas de uma ciência de rigor, com evidência apodítica; b) analisa dados inerentes à consciência e não especula sobre cosmovisões, isto é, funda-se na essência dos fenômenos e na subjetividade transcendental, pois, as essências só existem na consciência; c) é descritivo, conduzindo a resultados específicos e cumulativos, como no caso de investigações científicas; não faz inferências nem conduz a teorias metafísicas; d) como conhecimento fundado nas essências é um saber absolutamente necessário, em oposição ao conhecimento fundado na experiência empírica dos fatos contingentes; e) conduz à certeza e, por conseguinte, é uma disciplina a priori; f) é uma atividade científica no melhor sentido da palavra, sem ser, ao mesmo tempo, esmagada pelas pressuposições da ciência e sofrer suas limitações. Busca a raiz de toda a atividade filosófica e científica."

${ }^{15}$ Cf. STEIN, E. Mundo vivido: das vicissitudes e dos usos de um conceito da fenomenologia. Porto Alegre: Edipucrs, 2004, p. 132.

${ }^{16}$ Cf. HUSSERL, E. A crise da humanidade européia e a filosofia. Trad. e introdução Urbano Zilles. Porto Alegre: Edipucrs, 2002, p. 41.

${ }^{17}$ Cf. HUSSERL, E. A crise da humanidade européia e a filosofia. Trad. e introdução Urbano Zilles. Porto Alegre: Edipucrs, 2002, p. 47: "A fase da crise de Husserl caracteriza-se pelo conceito de Lebenswelt (mundo da vida). Opõe o Lebenswelt ao mundo das ciências. Tenta fundamentar o último no primeiro, no mundo pré-científico. Segundo ele, a própria ciência emerge de algo anterior a ela mesma, do campo das experiências pré-científicas e pré-categoriais, ou seja, de um a priori concreto, que chama de Lebenswelt ou Lebensumwelt. Em outras palavras, pergunta pelas condições a priori de possibilidade das ciências ao nível histórico e existencial."

${ }^{18}$ Cf. HUSSERL, E. A crise da humanidade européia e a filosofia. Trad. e introdução Urbano Zilles. Porto Alegre: Edipucrs, 2002, p. 90: "Trata-se de problemas procedentes da ingenuidade, em virtude da qual a ciência objetivista toma o que ela chama o mundo objetivo como sendo o universo de todo o existente, sem considerar que a subjetividade criadora da ciência não pode ter seu lugar legítimo em nenhuma ciência objetiva. Aquele que é formado nas ciências naturais julga evidente que todos os fatores puramente subjetivos devem ser excluídos e que o método científico-natural determina, em termos objetivos, o que tem sua figuração nos modos subjetivos da representação. Por isso busca o objetivamente verdadeiro também no plano psíquico. Ao mesmo tempo admite-se, com isso, que os fatores subjetivos excluídos pelo físico serão investigados pela psicologia precisamente como algo psíquico e naturalmente uma psicologia psico-física. Mas o investigador da natureza não se dá conta que o fundamento permanente de seu trabalho mental, subjetivo, é o mundo circundante (Lebenswelt) vital, que constantemente é pressuposto como base, como o terreno da atividade, sobre o qual suas perguntas e métodos de pensar adquirem um sentido." (Utilizamos esta obra, uma vez que não tivemos acesso à obra A crise das ciências europeias e a fenomenologia transcendental - uma introdução à Filosofia Fenomenológica. Rio de Janeiro: Forense Universitária, 2012.).

${ }^{19}$ Cf. HUSSERL, E. A crise da humanidade européia e a filosofia. Trad. e introdução Urbano Zilles. Porto Alegre: Edipucrs, 2002, p. 94: "Esta supera o objetivismo naturalista e todo objetivismo em geral da única maneira possível: o sujeito filosofante parte do seu eu, mais precisamente, ele se considera apenas como executor (Vollzieher) de todos os atos dotados de validade, tornando-se um espectador puramente teórico. Nesta atitude consegue-se construir uma ciência do espírito absolutamente autônoma, no modo de uma consequente compreensão de si mesmo e compreensão do mundo como obra do espírito."

\begin{tabular}{|c|c|l|l|l|l|}
\hline intuitio & $\begin{array}{c}\text { ISSN } \\
1983-4012\end{array}$ & Porto Alegre & Vol.10 $-\mathrm{N}^{\circ} .1$ & $\begin{array}{l}\text { Julho } \\
2017\end{array}$ & p. 94-106 \\
\hline
\end{tabular}


O mundo da vida é o âmbito das formações de sentido originárias, ou seja, é o a priori dado com a subjetividade, do qual partem as ciências. Há uma correlação consciência-mundo. Portanto, a subjetividade transcendental deve estar no centro da reflexão, havendo, assim, a recuperação do mundo da vida, sobre o qual as ciências são constituídas.

A proposta husserliana de mundo da vida não parece satisfazer devido a sua ambiguidade: tentar dar conta de um princípio do conhecimento e das questões históricas. ${ }^{20}$

Posto isto, chegamos a Heidegger. No paradigma heideggeriano não há mais um sujeito absoluto nem uma teoria do conhecimento que fundamenta tudo. Há, pois, um ente existente concretamente, serno-mundo (Dasein), que é possibilidade. ${ }^{21} \mathrm{O}$ conceito de ser-no-mundo ${ }^{22}$ é pensado por Heidegger como a condição humana primeira ${ }^{23}$ em sua experiência originária.

O conceito de ser-no-mundo se coloca na tentativa de encontrar uma condição de possibilidade tanto para o discurso sobre a razão (teoria do conhecimento), quanto para o discurso sobre a realidade (ontologia). Por intermédio da compreensão do modo de ser do ser-no-mundo, o conceito heideggeriano de mundo pretende descrever a condição de possibilidade da realidade e do ente existente concretamente. O conceito de mundo antecede a relação sujeito-objeto e é a condição de possibilidade das relações. ${ }^{24}$ Dito

${ }^{20}$ Cf. STEIN, E. Mundo vivido: das vicissitudes e dos usos de um conceito da fenomenologia. Porto Alegre: Edipucrs, 2004, p. 135: "Poderíamos dizer que a idéia de mundo vivido em Husserl, se não satisfaz, é justamente porque traz em si essa ambigüidade de querer ser, ao mesmo tempo, um princípio do conhecimento e um princípio explicativo do lado histórico da condição humana. A única maneira de fugir disso é ir para um lugar em que afirmamos a idéia de mundo, que não é mais do nível nem do racionalismo, nem do idealismo, ou melhor, que se coloca a nível de superar a diferença entre sujeito e objeto, porque é anterior à relação sujeito-objeto. Esta é, no sentido próprio, a marca do paradigma heideggeriano."

${ }^{21}$ Cf STEIN, E. Mundo vivido: das vicissitudes e dos usos de um conceito da fenomenologia. Porto Alegre: Edipucrs, 2004, p. 133: [...] A idéia de mundo em Heidegger não é nem mais a idéia de um mundo que a razão constrói (portanto, a pura racionalidade), nem a idéia de mundo como a realidade exterior existente independentemente do sujeito. A idéia de mundo é o modo de ser e a condição de possibilidade de ser da própria existência humana. Isto significa, então, que ser-no-mundo é uma espécie de expressão sintética que surgiu frente às críticas ao fundamentalismo kantiano, ao holismo hegeliano e à insuficiência das teorias da vida, das teorias psicológicas, etc., que tentavam justificar a história concreta ou o caráter histórico dos sujeitos."

${ }^{22}$ Cf. STEIN, E. Mundo vivido: das vicissitudes e dos usos de um conceito da fenomenologia. Porto Alegre: Edipucrs, 2004, p. 141: "Heidegger, a partir de uma determinada reflexão sobre o conceito de cosmos, vislumbrou, de uma forma genética, um conceito de mundo com um duplo sentido. No primeiro sentido, ele apresenta o mundo enquanto continente, totalidade; no segundo sentido, o mundo enquanto mundo do homem. No segundo sentido, quanto ao homem, Heidegger subdivide este conceito em duas partes: o homem mundano, habitante do mundo; e o homem divino, temente a Deus. Portanto, é na cosmologia, na história deste conceito desde os gregos, que Heidegger busca o seu conceito de mundo. E, da sua análise sobre o homem, surge um elemento que se liga à teologia racional. Extraindo da cosmologia o duplo conceito de mundo e de homem, Heidegger chega, em sua análise, ao conceito de ser-no-mundo."

${ }^{23}$ Cf. STEIN, E. Mundo vivido: das vicissitudes e dos usos de um conceito da fenomenologia. Porto Alegre: Edipucrs, 2004, p. 134: “[...] Quando digo 'condição humana' não é a condição de ser existente, mas a condição de possibilidade de o ser humano conhecer, afirmar a verdade, satisfazer-se com princípios, descrever a historicidade, etc."

${ }^{24}$ Cf. STEIN, E. Mundo vivido: das vicissitudes e dos usos de um conceito da fenomenologia. Porto Alegre: Edipucrs, 2004, p. 134: “[...] Quer dizer, em Heidegger o conceito de existência, de Dasein, de ser-no-mundo é um conceito que se coloca numa tentativa de encontrar uma condição de possibilidade de todo discurso sobre a razão,

\begin{tabular}{|c|c|l|l|l|l|}
\hline intuitio & $\begin{array}{c}\text { ISSN } \\
1983-4012\end{array}$ & Porto Alegre & Vol.10- No.1 & $\begin{array}{l}\text { Julho } \\
2017\end{array}$ & p. 94-106 \\
\hline
\end{tabular}


de outro modo, a partir da possibilidade que o ser-no-mundo mesmo é, estrutura-se a condição de possibilidade de se pensar a realidade e a questão da verdade. ${ }^{25}$

A partir da formulação da pergunta “o que é mundo?", Heidegger aponta, na obra Os Conceitos Fundamentais da Metafísica: Mundo, Finitude, Solidão, ${ }^{26}$ para o fato de haver diversos caminhos para levantar a questão, quais sejam: 1. a consideração historiográfica da história do conceito de mundo; 2. o desdobramento do conceito de mundo a partir de nossa compreensão cotidiana de mundo; e 3. a consideração comparativa. O terceiro caminho é o escolhido por Heidegger, cujo ponto de apoio são três teses. $^{27}$

Passemos, pois, à formulação heideggeriana do conceito de mundo, a partir das três teses apresentadas pelo filósofo, a saber: 1. "a pedra (o material) é sem-mundo"; 2. "o animal é pobre de mundo"; e 3. "o homem é formador de mundo". ${ }^{28}$

\section{A FORMULAÇÃO DO CONCEITO DE MUNDO}

Heidegger inicia a caracterização comparativa do conceito de mundo pela tese intermediária "o animal é pobre de mundo". O filósofo afirma que ao se olhar constantemente para a ausência de mundo da pedra e para a formação de mundo do homem, consideramos o animal e a sua pobreza de mundo. A pobreza de mundo do animal não indica um nivelamento depreciador, ${ }^{29}$ mas sim, indica uma privação de mundo, uma vez que o conceito de "mundo significa inicialmente a soma do ente acessível, seja para o animal, seja para o homem, variável segundo a abrangência e a profundidade da penetração."30

$\mathrm{O}$ mundo de qualquer animal não se restringe àquilo que ele pode abranger, como o mundo ambiente no qual o animal se encontra, mas sim, também no modo de penetração no que é acessível ao animal. Ao aproximarmos de nós a diferença entre "pobre de mundo" e "formador de mundo", essa se

enquanto teoria do conhecimento, e de todo discurso sobre a realidade, enquanto uma ontologia ou metafísica. Por isso, Heidegger vai dizer que a ideia de mundo antecede a relação sujeito-objeto, que somente se dá na medida em que a relação que se dará aí tem uma condição de possibilidade e, logo, um fundamento."

${ }^{25}$ Cf. STEIN, E. Mundo vivido: das vicissitudes e dos usos de um conceito da fenomenologia. Porto Alegre: Edipucrs, 2004, p. 135.

${ }^{26}$ HEIDEGGER, M. Os Conceitos fundamentais da metafísica: mundo, finitude, solidão. Trad. Marco Casanova. Rio de Janeiro: Forense Universitária, 2006.

${ }^{27}$ Cf. HEIDEGGER, M. Os conceitos fundamentais da metafísica: mundo, finitude, solidão. Trad. Marco Casanova. Rio de Janeiro: Forense Universitária, 2006, p. 214.

${ }^{28}$ Cf. HEIDEGGER, M. Os conceitos fundamentais da metafísica: mundo, finitude, solidão. Trad. Marco Casanova. Rio de Janeiro: Forense Universitária, 2006, p. 207.

${ }^{29}$ Cf. HEIDEGGER, M. Os conceitos fundamentais da metafísica: mundo, finitude, solidão. Trad. Marco Casanova. Rio de Janeiro: Forense Universitária, 2006, p. 225: “Todo e qualquer animal, toda e qualquer espécie de animal é tão plena quanto outra. Por tudo o que foi dito torna-se evidente que, desde o princípio, o discurso da pobreza de mundo e da formação de mundo não deve ser tomado no sentido de uma ordem de valores depreciativa."

${ }^{30}$ Cf. HEIDEGGER, M. Os conceitos fundamentais da metafísica: mundo, finitude, solidão. Trad. Marco Casanova. Rio de Janeiro: Forense Universitária, 2006, p. 224.

\begin{tabular}{|c|c|c|c|c|c|}
\hline intuitio & $\begin{array}{c}\text { ISSN } \\
1983-4012\end{array}$ & Porto Alegre & Vol.10 $-\mathrm{N}^{\circ} .1$ & $\begin{array}{l}\text { Julho } \\
2017\end{array}$ & p. 94-106 \\
\hline
\end{tabular}


revela como uma diferença de grau dos níveis de plenitude na posse do ente respectivamente acessível, ${ }^{31}$ ou seja, há uma diferença ontológica.

O modo de ser do animal, que denominamos "vida", permite que ele tenha acesso ao que está ao seu lado, quer dizer, ao meio no qual se encontra. Ser pobre de mundo não significa não possuir nada ou menos do que o outro. $\mathrm{O}$ animal possui o seu mundo ambiente, com o qual se conecta. $\mathrm{O}$ animal está, porém, encerrado em seu mundo, uma vez que este não se amplia nem se estreita. $\mathrm{O}$ acesso ao ente se dá de maneira diversa. Destarte, o animal possui mundo, embora com limites estreitos. ${ }^{32}$

Diferentemente dos animais, os entes materiais não possuem nenhum acesso ao ente. A tese "a pedra é sem-mundo" indica que os entes materiais, por exemplo, a pedra, possuem tal constituição que não podem nem mesmo ser privados de algo do gênero do mundo. Uma vez que mundo é o que é acessível, a pedra é sem mundo. Encontramos uma pedra, por exemplo, no caminho, no solo. A pedra se encontra sobre o solo, mas não o tateia, como um animal o faz. E uma vez que é jogada de um lado a outro, ali permanece. A pedra é. ${ }^{33}$ A essência da pedra é a ausência de acesso. ${ }^{34}$ A pedra é sem mundo.

O modo de ser de uma coisa material (sem-mundo) possui uma diferença em relação ao modo de ser dos animais (pobre de mundo). Também, o modo de ser do ser humano (formador de mundo) se difere em relação a ambos, como veremos a seguir.

Após a caracterização comparativa das duas primeiras teses "a pedra é sem-mundo" e "o animal é pobre de mundo", Heidegger busca a justificação para a terceira tese "o homem é formador de mundo", com o objetivo de caracterizar a essência do mundo. ${ }^{35}$

Heidegger busca esclarecer o que significa a expressão formação de mundo, desencobrindo “"o que o mundo é e como ele é'; e 'se e em que sentido temos o direito de falar efetivamente do ser do mundo"". ${ }^{36}$ E, para tal, são caracteres importantes do fenômeno do mundo: "1. a abertura do ente enquanto

${ }^{31}$ Cf. HEIDEGGER, M. Os conceitos fundamentais da metafísica: mundo, finitude, solidão. Trad. Marco Casanova. Rio de Janeiro: Forense Universitária, 2006, p. 224.

${ }^{32}$ Cf. HEIDEGGER, M. Os conceitos fundamentais da metafísica: mundo, finitude, solidão. Trad. Marco Casanova. Rio de Janeiro: Forense Universitária, 2006, p. 230.

${ }^{33}$ Cf. HEIDEGGER, M. Os conceitos fundamentais da metafísica: mundo, finitude, solidão. Trad. Marco Casanova. Rio de Janeiro: Forense Universitária, 2006, p. 228: "Porque a pedra em seu ser-pedra não tem absolutamente nenhum acesso a algo diverso, em meio ao qual ela advém, para alcançar e possuir este algo diverso enquanto tal, ela também não pode absolutamente ser privada de. A pedra é. Ou seja: ela é isto ou aquilo, e é enquanto tal aqui ou lá.”

${ }^{34}$ Cf. HEIDEGGER, M. Os conceitos fundamentais da metafísica: mundo, finitude, solidão. Trad. Marco Casanova. Rio de Janeiro: Forense Universitária, 2006, p. 228: "[...] essa ausência de acesso possibilita justamente o ser específico, isto é, o contexto ontológico da natureza física material e a ordem de suas leis."

${ }^{35}$ COSTA, J. B. da. Análise da linguagem: a condição de possibilidade dos enunciados filosóficos. Ijuí: Ed. Unijuí, 2013, p. 73: “Após analisar as duas primeiras teses: 'a pedra é sem mundo' e 'o animal é pobre de mundo', ele busca justificar a tese 'o homem é formador de mundo', a fim de caracterizar a essência do mundo a partir da questão central da metafísica, que é a da totalidade, uma vez que a 'metafísica é uma interrogação na qual nos inserimos de modo questionador na totalidade e perguntamos de uma tal maneira que, na questão, nós mesmos, os questionadores, somos colocados em questão'."

${ }^{36}$ COSTA, J. B. da. Análise da linguagem: a condição de possibilidade dos enunciados filosóficos. Ijuí: Ed. Unijuí,

\begin{tabular}{|c|c|c|c|c|c|}
\hline intuitio & $\begin{array}{c}\text { ISSN } \\
1983-4012\end{array}$ & Porto Alegre & Vol.10- No.1 & $\begin{array}{c}\text { Julho } \\
2017\end{array}$ & p. 94-106 \\
\hline
\end{tabular}


O Homem é Formador de Mundo: Mundo Como Conceito Metafísico Segundo Martin Heidegger

ente; 2. o 'enquanto'; 3. a ligação com o ente enquanto o deixar e não-deixar-ser, o assumir uma atitude em relação a... a postura e o caráter de si-próprio (ipseidade)." ${ }^{, 37}$

A proposta heideggeriana é partir do que já é conhecido, ou seja, da cotidianidade, pois "onde quer que o mundo se dê, aí o ente está manifesto". ${ }^{38}$ Perguntar sobre a formação de mundo é perguntar pelo homem, perguntar por nós mesmos, e, consequentemente, constatar o problema da finitude. ${ }^{39} \mathrm{O}$ homem é o formador de mundo, e, somente sobre este fundamento, ele pode existir.

Mundo é a abertura do ente enquanto tal na totalidade. O enquanto é um momento estrutural da proposição, ${ }^{40}$ o qual expressa algo, e está compreendido em todo e qualquer enunciado proposicional. ${ }^{41} \mathrm{~A}$ proposição enunciativa é uma construção necessária no discurso humano, pertencendo à essência do discurso cotidiano, e, ao avançar através dela, a sua essência se mostra como compreensível. ${ }^{42} \mathrm{O}$ problema da proposição é considerado por conduzir ao problema do mundo. ${ }^{43}$

Heidegger busca na tradição, mais precisamente em Aristóteles, a caracterização da proposição enunciativa, ${ }^{44}$ e passa a analisar o logos na perspectiva aristotélica. Assim, logos, linguagem e mundo se

2013, p. 74.

${ }^{37}$ Cf. HEIDEGGER, M. Os conceitos fundamentais da metafísica: mundo, finitude, solidão. Trad. Marco Casanova. Rio de Janeiro: Forense Universitária, 2006, p. 315.

${ }^{38}$ Cf. HEIDEGGER, M. Os conceitos fundamentais da metafísica: mundo, finitude, solidão. Trad. Marco Casanova. Rio de Janeiro: Forense Universitária, 2006, p. 315.

${ }^{39}$ COSTA, J. B. da. Análise da linguagem: a condição de possibilidade dos enunciados filosóficos. Ijuí: Ed. Unijuí, 2013, p. 76: "Tomar o homem como tema, segundo Heidegger, significa que perguntamos por nós mesmos; por um ente que como tarefa, nos é dado ser, pela respectiva existência do homem, pela responsabilização do homem e seu ser-aí, e sua finitude que lhe é intrínseca."

${ }^{40}$ Cf. HEIDEGGER, M. Os conceitos fundamentais da metafísica: mundo, finitude, solidão. Trad. Marco Casanova. Rio de Janeiro: Forense Universitária, 2006, p. 346: Do termo proposição entende-se: 1. proposição enquanto um modo de estabelecimento; e 2. proposição enquanto o que é estabelecido.

${ }^{41}$ Cf. HEIDEGGER, M. Os conceitos fundamentais da metafísica: mundo, finitude, solidão. Trad. Marco Casanova. Rio de Janeiro: Forense Universitária, 2006, p. 346.

${ }^{42}$ Cf. HEIDEGGER, M. Os conceitos fundamentais da metafísica: mundo, finitude, solidão. Trad. Marco Casanova. Rio de Janeiro: Forense Universitária, 2006, p. 348.

${ }^{43}$ COSTA, J. B. da. Análise da linguagem: a condição de possibilidade dos enunciados filosóficos. Ijuí: Ed. Unijuí, 2013, p. 80: "Para Heidegger, somente percorrendo a estrutura da enunciação chegaremos a um esclarecimento correto sobre o enquanto, e sobre sua conexão com a abertura mesma, e com isso, sobre a essência do mundo. Para isso ele resgata na Filosofia antiga os significados de 'enunciado' e 'juízo' chamados de logos, que é o tema principal da lógica. O problema do mundo será reconduzido ao problema do logos. Sendo a Lógica a própria base da Metafísica, 'o problema do mundo enquanto problema fundamental da metafísica é trazido pra o interior da Lógica'."

${ }^{44}$ Não é objetivo deste trabalho discutir cada um dos pontos apresentados por Heidegger no §72, o qual apresenta a caracterização da proposição enunciativa em Aristóteles. Cabe, contudo, apresentar os pontos, quais sejam: a) O $\log o s$, tomado em sua universalidade: discurso enquanto significação, enquanto dar a entender. $\mathrm{O}$ acontecimento de um acordo que retém as coisas juntas como condição de possibilidade do discurso; b) $\mathrm{O}$ discurso mostrador em sua possibilidade de retirar do velamento - velar; c) A percepção formadora de unidade, de algo enquanto algo, a estrutura "enquanto" como fundamento essencial para a possibilidade de retirar do velamento-velar inerente ao logos, mostrador; d) A percepção formadora de unidade de algo enquanto inerente à enunciação afirmativa e negativa como uma reunião que separa; e) A mostração própria ao enunciado como o deixar-ver o ente enquanto o que é e como é; f) Determinação recapituladora da essência do enunciado simples e determinação de seus componentes singulares; g) Reunião como significação do "é" no enunciado; h) Quididade, fato de ser e ser-

\begin{tabular}{|c|c|l|l|l|l|}
\hline intuitio & $\begin{array}{c}\text { ISSN } \\
1983-4012\end{array}$ & Porto Alegre & Vol.10- No.1 & $\begin{array}{l}\text { Julho } \\
2017\end{array}$ & p. 94-106 \\
\hline
\end{tabular}


encontrarão em uma conexão interna, conectados à definição heideggeriana de homem: "a ele pertence um estar-aberto para, a qual possui um caráter da percepção de algo enquanto algo." ${ }^{45} \mathrm{O}$ fundamento da possibilidade interna do logos é o que se chama de formação de mundo.

Como dito, o mundo é a abertura do ente enquanto tal na totalidade. Ao perguntarmos pelo "enquanto", afirma Heidegger, adentramos no fenômeno do mundo. "Em contraposição ao estar-abertopara... do animal, o ‘enquanto' é algo distintivo disto para o que o homem está aberto. Para o animal, o estar-aberto-para... implica a absorção na perturbação. Este 'enquanto' é pertinente a uma ligação." 46

A essência do "enquanto" segue com a pergunta sobre a essência do "é", ou seja, do ser. Com isso, o "ser" e o "enquanto" apontam para a mesma origem, ambos remetendo ao desdobramento do problema do mundo. O "enquanto" é um momento estrutural do que chamamos de mundo, e o "na totalidade" se refere à estrutura do mundo, uma vez que remete à integração que nela se forma. ${ }^{47}$

Após apresentar a diferença ontológica ${ }^{48}$ entre ser e ente, ${ }^{49}$ pois esta é o momento central a partir do qual o problema do mundo pode ser compreendido, Heidegger aponta o projeto como estrutura

verdadeiro como interpretações possíveis da cópula. A multiplicidade não dispersa das significações como a essência primária da cópula.

${ }^{45}$ COSTA, J. B. da. Análise da linguagem: a condição de possibilidade dos enunciados filosóficos. Ijuí: Ed. Unijuí, 2013, p. 85.

${ }^{46}$ Cf. HEIDEGGER, M. Os conceitos fundamentais da metafísica: mundo, finitude, solidão. Trad. Marco Casanova. Rio de Janeiro: Forense Universitária, 2006, p. 381.

${ }^{47}$ Cf. HEIDEGGER, M. Os conceitos fundamentais da metafísica: mundo, finitude, solidão. Trad. Marco Casanova. Rio de Janeiro: Forense Universitária, 2006, p. 400: "Uma vez que o "enquanto" é, porém, um momento estrutural do que chamamos mundo e mundo é tomado como a abertura do ente enquanto tal na totalidade, com aquele acontecimento fundamental (triplo) nos deparamos com o acontecimento, no interior do qual tem lugar o que chamamos formação de mundo. Isto se torna ainda mais verossímil, à medida que, segundo a análise formal, o "na totalidade" se refere à estrutura do mundo - este "na totalidade", que diz respeito evidentemente à integração, nela se forma."

${ }^{48}$ Cf. HEIDEGGER, M. Os conceitos fundamentais da metafísica: mundo, finitude, solidão. Trad. Marco Casanova. Rio de Janeiro: Forense Universitária, 2006, p. 411: “A diferença ontológica é aquela que concerne ao ser do ente; a diferença na qual tudo o que há de ontológico se movimenta e que tudo o que há de ontológico pressupõe para a sua possibilidade interna; a diferença na qual o ser se diferencia do ente que ele ao mesmo tempo determina em sua constituição ontológica."

${ }^{49}$ Cf. HEIDEGGER, M. Os conceitos fundamentais da metafísica: mundo, finitude, solidão. Trad. Marco Casanova. Rio de Janeiro: Forense Universitária, 2006, p. 409, são nove os pontos da diferença entre ser e ente: "1. Desconsideramos constantemente esta diferença entre ser e ente, justamente onde a usamos constantemente: efetivamente a cada vez que dizemos 'é'; mas, antes de tudo, em toda atitude em relação ao ente (quididade, ser-tal e fato de ser); 2. Fazemos constantemente uso desta diferença, sem saber ou poder constatar, que aplicamos aí um saber qualquer, uma regra, uma proposição e coisas do gênero; 3 . A diferença é - abstraindo-se de seu conteúdo, do aí diferenciado enquanto tal - obscura segundo a dimensão da diferencialidade. Não conseguimos colocar o ser em um nível de comparação com o ente. Daí se entende que não se representa e toma conhecimento desta diferença em geral no sentido de algo passível de se tomar conhecimento; 4. Portanto, se não apresentamos esta diferença no sentido da diferenciação objetiva, então já sempre nos movimentamos no acontecimento da diferença. Não porque nós o empreendemos, mas porque ele acontece conosco enquanto um acontecimento fundamental de nosso ser-aí; 5. A diferença não acontece conosco arbitrariamente e de vez em quando, mas desde o fundamento e constantemente; 6. Pois se esta diferença não acontecesse, então não poderíamos nem mesmo - esquecendo a diferença - nos manter de início e na maioria das vezes juntos ao ente. Pois justamente para experimentar o que e como o ente sempre cada vez é nele mesmo, enquanto o ente que ele é, já precisamos compreender, mesmo que não conceitualmente, algo do

\begin{tabular}{|c|c|l|l|l|l|}
\hline intuitio & $\begin{array}{c}\text { ISSN } \\
1983-4012\end{array}$ & Porto Alegre & Vol.10- No.1 & $\begin{array}{l}\text { Julho } \\
2017\end{array}$ & p. 94-106 \\
\hline
\end{tabular}


originária da formação de mundo. Projeto é projeto de mundo. Projetar é o abrir-se para a possibilitação. "Nesta possibilitação é retirada do velamento a ligação mais originária entre o possível e o real, entre possibilidade e realidade em geral enquanto tal. ${ }^{, 50}$

O mundo se forma no acontecimento do projeto. Dito de outra maneira, algo se abre para possibilidades no projetar, e, assim, forma-se o mundo. ${ }^{51}$ Não há, assim, algo fixado ou determinado, mas sim, algo para o qual o Dasein deve continuamente se projetar. Há possibilidades. O Dasein é suas possibilidades, uma vez que o seu modo de ser envolve a noção de projeção.

O Dasein é o ente que irrompe para o ser, possuindo assim, um modo próprio distinto dos demais. O Dasein é o ente que existe, isto é, "que ele é na essência de seu ser um movimento para fora de si mesmo, sem, porém, abandonar a si. O homem é aquele não-poder-permanecer, e, no entanto, não-poderdeixar o seu lugar. ${ }^{, 52}$ Ao se projetar, o Dasein se joga constantemente à possibilidade. Assim, o Dasein é e se constitui em meio à jogada.

\section{CONSIDERAÇÕES FINAIS}

O nosso artigo teve como objetivo tratar, brevemente, do conceito de mundo apresentado por Martin Heidegger na obra Os conceitos fundamentais da metafísica: mundo, finitude, solidão. Para tanto, dividimos o nosso trabalho em dois momentos: 1. Contextualização do paradigma heideggeriano; e 2. A formulação do conceito de mundo.

No primeiro momento contextualizamos o paradigma heideggeriano, o qual surge frente à pretensão fundamentalista de Kant e à pretensão holista de Hegel. Uma vez que as teorias kantiana e

gênero da quididade e do fato-de-ser; 7. A diferença não acontece apenas constantemente, mas a diferença já precisa ter acontecido, se quisermos experimentar um ente em seu ser-tal-e-tal. Nunca experimentamos ulteriormente, depois do ente e a partir do ente, algo sobre o ser. Ao contrário, o ente, onde quer e como quer que nos aproximemos dele, já se encontra sob a luz do ser. Portanto, tomada metafisicamente, a diferença encontra-se no começo do ser-aí mesmo; 8. Esta diferença entre ser e ente já sempre acontece de tal modo que o 'ser', apesar de indiferente, é a todo momento compreendido em uma articulação inexpressa no mínimo quanto à quididade e ao fato-de-ser. Assim, o homem sempre se encontra em meio à possibilidade de perguntar: o que é isto? E: isto é efetivamente ou não é? $\mathrm{O}$ porquê de justamente a quididade e o fato-de-ser pertencem à essência originária do ser é um dos problemas mais profundos que acham seu termo nesta rubrica; um problema que certamente nunca chegou realmente a se tornar até aqui um problema, mas sempre se mostrou como uma obviedade. Tal como os senhores podem ver, por exemplo, no interior da metafísica tradicional e da ontologia, foi esta que sempre orientou aí a diferença entre essentia e existência, quididade e fato-de-ser do ente. Utiliza-se esta diferença de modo tão óbvio quanto o dia e a noite; 9 . A partir de todos os oito momentos precedentes, deduzimos a unidade desta diferença, e, ao mesmo tempo, a sua universalidade."

${ }^{50}$ Cf. HEIDEGGER, M. Os conceitos fundamentais da metafísica: mundo, finitude, solidão. Trad. Marco Casanova. Rio de Janeiro: Forense Universitária, 2006, p. 417.

${ }^{51}$ Cf. HEIDEGGER, M. Os conceitos fundamentais da metafísica: mundo, finitude, solidão. Trad. Marco Casanova. Rio de Janeiro: Forense Universitária, 2006, p. 418: "No acontecimento do projeto forma-se mundo, isto é, no projetar eclode algo, algo abre-se para possibilidades e irrompe, assim, no real enquanto tal, para experimentar a si mesmo como irrupção, como realmente sendo um meio ao que agora pode ser aberto enquanto ente."

${ }^{52}$ Cf. HEIDEGGER, M. Os conceitos fundamentais da metafísica: mundo, finitude, solidão. Trad. Marco Casanova. Rio de Janeiro: Forense Universitária, 2006, p. 418.

\begin{tabular}{|c|c|l|l|l|l|}
\hline intuitio & $\begin{array}{c}\text { ISSN } \\
1983-4012\end{array}$ & Porto Alegre & Vol.10 $-\mathrm{N}^{\circ} .1$ & $\begin{array}{l}\text { Julho } \\
2017\end{array}$ & p. 94-106 \\
\hline
\end{tabular}


hegeliana não dão conta dos processos de justificação do conhecimento humano e no processo histórico da filosofia, o que restou foi a recuperação do campo do vivido na filosofia. Quem o faz é Husserl. A proposta husserliana busca elaborar as condições de possibilidade do sujeito vivido, através do conceito de mundo vivido reconstruído na interioridade da razão transcendental. Devido a sua ambiguidade, pois tenta dar conta de um princípio do conhecimento e das questões históricas, a proposta husserliana não satisfaz. Assim, surge o paradigma heideggeriano, o qual pretende encontrar uma condição de possibilidade tanto para o discurso sobre a razão, quanto para o discurso sobre a realidade.

No segundo momento do nosso artigo, tratamos da formulação do conceito de mundo na obra $O s$ conceitos fundamentais da metafísica: mundo, finitude, solidão. A partir da pergunta "o que é mundo?", Heidegger formula o conceito de mundo. A formulação heideggeriana se dá por consideração comparativa entre três teses, quais sejam: 1. "a pedra (o material) é sem-mundo"; 2. "o animal é pobre de mundo"; e 3. "o homem é formador de mundo.

Heidegger inicia a caracterização comparativa do conceito de mundo pela tese intermediária "o animal é pobre de mundo", a qual analisa o modo de ser do animal, cujo acesso ao ente se dá de maneira diversa e com limites estreitos. Desse modo, ao olharmos para a ausência de mundo da pedra e para a formação de mundo do homem, consideramos o animal e a sua pobreza de mundo. A pobreza de mundo do animal indica uma privação de mundo, pois o conceito de mundo, inicialmente, significa a soma do ente acessível, variável segundo a abrangência e a profundidade da penetração. Há uma diferença ontológica entre "podre de mundo" e "formador de mundo", pois há diferença de grau dos níveis de plenitude na posse do ente respectivamente acessível. O modo de ser do animal permite que ele tenha acesso ao meio no qual se encontra. Porém, acesso do animal é limitado, encerrando-o em seu mundo, uma vez que este não se amplia nem se estreita.

Após a análise da tese intermediária, Heidegger analisa a tese "a pedra é sem-mundo", discutindo acerca dos entes materiais, os quais possuem tal constituição que a sua essência é a ausência de acesso ao ente. A constituição dos entes materiais é tal que estes não podem nem mesmo ser privados de algo do gênero do mundo. A essência da pedra é a ausência de acesso, e uma vez que mundo é o que é acessível, a pedra é sem-mundo.

Por fim, após a caracterização comparativa entre as duas primeiras teses, Heidegger busca a justificação para a terceira tese "o homem é formador de mundo", com o objetivo de caracterizar a essência de mundo. Mundo é a abertura do ente enquanto tal na totalidade. O enquanto é o momento estrutural da proposição e é algo distintivo disto para o que o homem está aberto. O enquanto é pertinente a uma ligação, e sua essência segue com a pergunta sobre a essência do "é" (ser). O "ser" e o "enquanto" remetem ao desdobramento do problema do mundo. O "enquanto" é um momento estrutural do que chamamos de mundo, e o "na totalidade" se refere à estrutura do mundo. A estrutura originária da

\begin{tabular}{|c|c|l|l|l|l|}
\hline intuitio & $\begin{array}{c}\text { ISSN } \\
1983-4012\end{array}$ & Porto Alegre & Vol.10- No.1 & $\begin{array}{l}\text { Julho } \\
2017\end{array}$ & p. 94-106 \\
\hline
\end{tabular}


formação de mundo é o projeto. Projeto é o projeto de mundo e projetar é o abrir-se para a possibilitação. Nesse sentido, não há algo fixado ou determinado ao Dasein, mas sim, há possibilidades. Assim, o mundo se forma no acontecimento do projeto.

\section{Referências}

COSTA, Joice Beatriz da. Análise da linguagem: a condição de possibilidade dos enunciados filosóficos. Ijuí: Ed. Unijuí, 2013.

HEIDEGGER, Martin. Ontologia (Hermenêutica da facticidade). Trad. Renato Kirchner. Petrópolis: Vozes, 2013.

Os conceitos fundamentais da metafísica: mundo, finitude, solidão. Trad. Marco Casanova. Rio de Janeiro: Forense Universitária, 2006.

HUSSERL, E. A crise da humanidade européia e a filosofia. Trad. e introdução Urbano Zilles. Porto Alegre: Edipucrs, 2002.

MEARLEU_PONTY, “O Filósofo e sua sombra”. Os Pensadores, São Paulo: Abril Cultural, 1980.

STEIN, Ernildo. Uma breve introdução à filosofia. Ijuí: Ed. Unijuí, 2005.

Edipucrs, 2004. Mundo vivido: das vicissitudes e dos usos de um conceito da fenomenologia. Porto Alegre:

Recebido em: 20/04/2017

Aprovado para a publicação em: 06/06/2017

\begin{tabular}{|c|c|c|c|c|c|}
\hline intuitio & $\begin{array}{c}\text { ISSN } \\
1983-4012\end{array}$ & Porto Alegre & Vol.10 - No.1 & $\begin{array}{l}\text { Julho } \\
2017\end{array}$ & p. 94-106 \\
\hline
\end{tabular}

